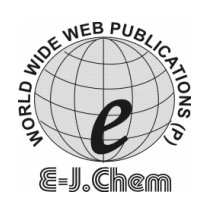

ISSN: 0973-4945; CODEN ECJHAO

E-Journal of Chemistry

http://www.e-journals.net

2009, 6(S1), S153-S158

\title{
Removal of Chromium from Aqueous Solution Using Modified Pomegranate Peel: Mechanistic and Thermodynamic Studies
}

\author{
TARIQ S. NAJIM* ${ }^{*}$ and SUHAD A. YASSIN \\ Duhok University, College of Education, \\ Chemistry Deptartment, Duhok, Iraq. \\ *AL-Mustansiriyah University, College of Science, \\ Chemistry Department, Baghdad, Iraq. \\ tariq_pru@yahoo.com
}

Received 14 March 2009; Accepted 10 May 2009

\begin{abstract}
Modified pomegranate peel (MPGP) and formaldehyde modified pomegranate peel (FMPGP) were prepared and used as adsorbent for removal of $\mathrm{Cr}(\mathrm{VI})$ ions from aqueous solution using batch process. The temperature variation study of adsorption on both adsorbents revealed that the adsorption process is endothermic, from the positive values of $\Delta \mathrm{H}^{\circ}$. These values lie in the range of physisorption. The negative values of $\Delta \mathrm{G}^{\circ}$ show the adsorption is favorable and spontaneous. On the other hand, these negative values increases with increase in temperature on both adsorbents, which indicate that the adsorption is preferable at higher temperatures. $\Delta \mathrm{S}^{\circ}$ values showed that the process is accompanied by increase in disorder and randomness at the solid solution interface due to the reorientation of water molecules and $\mathrm{Cr}(\mathrm{VI})$ ions around the adsorbent surface. The endothermic nature of the adsorption was also confirmed from the positive values of activation energy, Ea, the low values of Ea confirm the physisorption mechanism of adsorption. The sticking probability, $\mathrm{S}^{*}$, of $\mathrm{Cr}(\mathrm{VI})$ ion on surface of both adsorbents showed that the adsorption is preferable due to low values of $S^{*}\left(0<S^{*}<1\right)$, but $S^{*}$ values are lower for FMPGP indicating that the adsorption on FMPGP is more preferable.
\end{abstract}

Keywords: Mechanism, Modified pomegranate peel, Thermodynamic parameters, Activation energy, Sticking probability.

\section{Introduction}

One of the heavy metals that has been a major focus in water and wastewater treatment is chromium and the hexavalent form of it has been considered to be more hazardous due to its carcinogenic properties ${ }^{1}$. Chromium has been considered as one of the top $16^{\text {th }}$ toxic pollutants 
and because of its carcinogenic and teratogenic characteristics on the public, it has become a serious health concern ${ }^{2}$. In recent years, chromium concentration have been increasing in coastal water through the electroplating industry, metal finishing, leather tanning, chrome preparation and inorganic chemical productions ${ }^{3}$. There are various methods to remove $\mathrm{Cr}(\mathrm{VI})$ including chemical precipitation, membrane process, ion exchange, liquid extraction and electrodialysis ${ }^{4}$. These methods are non-economical and have many disadvantages such as incomplete metal removal, high reagent and energy requirements, generation of toxic sluge or other waste products that require disposal or treatment. In contrast, the adsorption technique is one of the preferred methods for removal of heavy metals because of its efficiency and low $\operatorname{cost}^{5}$. Utilizing the waste material from agriculture and industries can make treatment process economical and solve the solid waste disposal problem. The feasibility of several low cost, non-conventional adsorbents obtained from agricultural and industrial wastes was explored. The present work based on pomegranate peel which is an agricultural waste from pomegranate juice industry as an adsorbent for $\mathrm{Cr}(\mathrm{VI})$ removal from aqueous solution, this study will focus on the evaluation of thermodynamic parameters for adsorption of $\mathrm{Cr}(\mathrm{VI})$ onto modified pomegranate peel (MPGPG) and formaldehyde modified pomegranate peel (FMPGP).

\section{Experimental}

Pomegranate peel was collected in the northern part of Iraq, dried in dark at atmospheric temperature, then milled and sieved to particle size of $500 \mu \mathrm{m}$. The milled pomegranate peel was divided into two parts. The first one was shaked with distilled water for overnight then filtered, this process was repeated for about ten times or until we get rid off all soluble colored materials or until we get constant weight. It was observed that more than $40 \%$ of pomegranate peel was soluble in water. The yield was dried in an air oven at $80{ }^{\circ} \mathrm{C}$ for overnight, then milled to $150 \mu \mathrm{m}$ particle size, this part was named as modified pomegranate peel (MPGP). The second part was reacted with $8 \%$ formaldehyde solution in a ratio of pomegranate peel to formaldehyde $1: 5 \mathrm{w} / \mathrm{v}$ at $60{ }^{0} \mathrm{C}$ for 4 hours ${ }^{6}$. The formaldehyde modified pomegranate peel (FMPGP) was filtered out, washed with deionized water to remove free formaldehyde and then activated at $80{ }^{\circ} \mathrm{C}$ for 24 hours in an air oven, the dried FMPGP was milled to $150 \mu \mathrm{m}$.

\section{Preparation of $\mathrm{Cr}(\mathrm{VI})$ solution and analysis}

A stock solution of $\mathrm{Cr}(\mathrm{VI}) 500 \mathrm{mg} / \mathrm{L}$ was obtained by dissolving $1.4144 \mathrm{~g}$ of $\mathrm{K}_{2} \mathrm{Cr}_{2} \mathrm{O}_{7}$ in $1 \mathrm{~L}$ of deionized water and the solution was used for further experimental solution preparation. The $\mathrm{pH}$ values were adjusted with $0.13 \mathrm{M} \mathrm{HNO}_{3}$ or $0.1 \mathrm{M} \mathrm{NaOH}$. Analytical grade reagents were used through out this study. The $\mathrm{Cr}(\mathrm{VI})$ content in the sorption solutions was determined by atomic absorption spectrophotometer type (AAnalyest 200 Perkin Elmer).

\section{Adsorption thermodynamics}

The batch experiments for determination of thermodynamic parameters were conducted using $0.1 \mathrm{~g}$ of MPGP or FMPGP adsorbents in $50 \mathrm{~mL}$ of $\mathrm{Cr}(\mathrm{VI})$ solution of different concentration at different temperatures, at the end of each experiment the sample were collected, filtered by Whatman filter paper No. 40, the filtrate was analyzed for residual Cr concentration.

\section{Results and Discussion}

\section{Temperature effect on the adsorption of Cr(VI) onto MPGP}

Thermodynamic parameters such as change in free energy $\Delta \mathrm{G}^{\circ}$, enthalpy $\Delta \mathrm{H}^{\circ}$ and entropy $\Delta \mathrm{S}^{\circ}$ were determined using the following equations ${ }^{7,8}$. 


$$
\begin{aligned}
& \mathrm{C}_{\text {solid }} \underset{\mathrm{k}_{1}}{\stackrel{\mathrm{k}_{2}}{\longrightarrow} \mathrm{C}_{\text {liquid }}} \\
& K_{0}=\frac{C_{\text {solid }}}{C_{\text {liquid }}} \\
& \Delta G^{0}=-R T \ln K_{0} \\
& \log K_{0}=\frac{\Delta S^{0}}{2.303 R}-\frac{\Delta H^{0}}{2.303 R T}
\end{aligned}
$$

Where, $\mathrm{K}_{0}$ is the equilibrium constant, $\mathrm{C}_{\text {solid }}$ is the concentration of $\mathrm{Cr}(\mathrm{VI})$ at the solid phase (adsorbent) at equilibrium, $\mathrm{C}_{\text {liquid }}$ is the liquid phase concentration of $\mathrm{Cr}(\mathrm{VI})$ at equilibrium, $\mathrm{T}$ is the absolute temperature $(\mathrm{K})$ and $\mathrm{R}$ is the gas constant. Vant Hoff equation was used to estimate the values of $\Delta \mathrm{H}^{\circ}$ and $\Delta \mathrm{S}^{\circ}$. From the intercept and slope of the plot of $\log \mathrm{K}_{0}$ vs. $1 / \mathrm{T}$ (Figure 1), the $\Delta \mathrm{S}^{\circ}$ and $\Delta \mathrm{H}^{\circ}$ can be determined. These values are presented in Table 1.

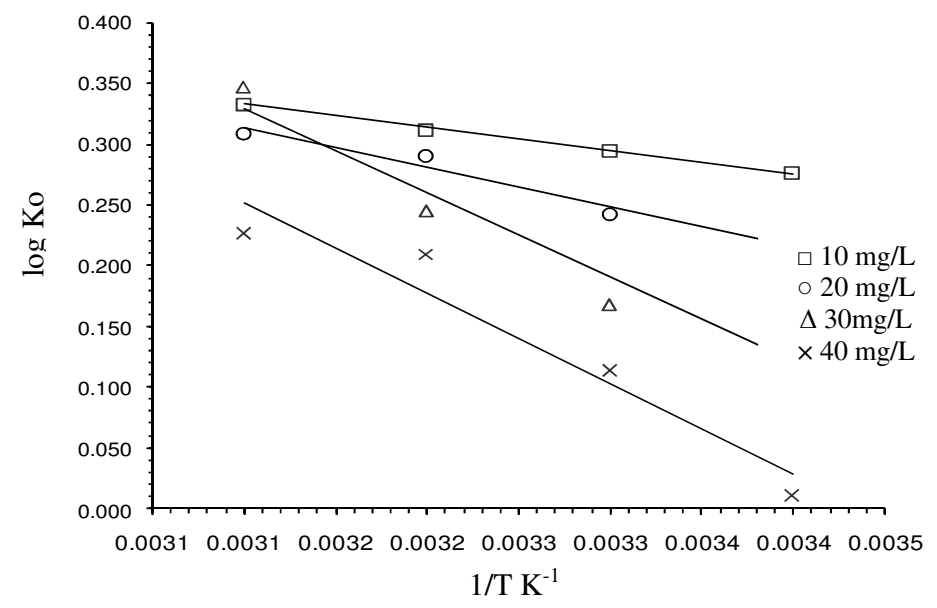

Figure 1. Plot of Van't Hoff equation for adsorption of $\mathrm{Cr}(\mathrm{VI})$ on to MPGP.

The values of $\Delta \mathrm{H}$ are within the range of 3.65 to $14.24 \mathrm{kJmol}^{-1}$ indicates the physisorption process. From the results, we could make out that physisorption is much more favorable for the adsorption of $\mathrm{Cr}(\mathrm{VI})$ onto MPGP. The positive values of $\Delta \mathrm{H}^{\circ}$ show the endothermic nature of adsorption and it governs the possibility of physical adsorption $^{9,10}$. Because in the case of physical adsorption, while increasing the temperature of the system, the extent of chromium ion adsorption increases, this rules out the possibility of chemisorption ${ }^{10}$. The values of $\Delta \mathrm{G}^{\circ}$ were obtained from the application of equation (2). The negative values of $\Delta G^{\circ}$ (Table 1), show that the adsorption is highly favorable and spontaneous. It was also observed that the negative values of $\Delta \mathrm{G}^{\circ}$ increases with increase in temperature, which indicate that the adsorption is preferable at high temperature, which was observed from the experimental data. The positive values of $\Delta \mathrm{S}^{\circ}$ (Table 1), show the increased disorder and randomness at the solid solution interface of chromium ion with MPGP, while the adsorption there are some structural changes in the chromium ion and the adsorbent occur. The adsorbed water molecules, which have displaced by the adsorbate species, gain more translational entropy than is lost by the adsorbate molecules, thus allowing the prevalence of randomness in the system ${ }^{8}$. 
Table 1. Thermodynamic parameters for the adsorption of $\mathrm{Cr}(\mathrm{VI})$ on to MPGP.

\begin{tabular}{|c|c|c|c|c|c|c|c|}
\hline \multirow{2}{*}{$\begin{array}{c}\mathrm{Cr}(\mathrm{VI}) \text { Con. } \\
\mathrm{mg} / \mathrm{L}\end{array}$} & \multirow{2}{*}{$\begin{array}{c}\Delta \mathrm{H}^{\circ} \\
\mathrm{kJ} \mathrm{mol}^{-1}\end{array}$} & \multirow{2}{*}{$\begin{array}{c}\Delta \mathrm{S}^{\circ} \\
\mathrm{Jmol}^{-1}\end{array}$} & \multicolumn{5}{|c|}{$\Delta \mathrm{G}^{0}, \mathrm{~kJ} \mathrm{~mol}^{-1}$} \\
\hline & & & $20{ }^{\circ} \mathrm{C}$ & $30{ }^{0} \mathrm{C}$ & $40{ }^{0} \mathrm{C}$ & $50{ }^{0} \mathrm{C}$ & $\mathrm{R}^{2}$ \\
\hline 10 & 3.651 & 17.686 & -1.547 & -1.708 & -1.870 & -2.061 & 0.9985 \\
\hline 20 & 6.232 & 25.318 & -1.214 & -1.405 & -1.739 & -1.911 & 0.9734 \\
\hline 30 & 13.244 & 47.355 & -0.795 & -0.973 & -1.466 & -2.143 & 0.9420 \\
\hline 40 & 14.236 & 48.944 & -0.058 & -0.661 & -1.249 & -1.401 & 0.9308 \\
\hline
\end{tabular}

In order to further support the assertion that physical adsorption is the predominant mechanism, the values of activation energy (Ea) and sticking probability $\left(\mathrm{S}^{*}\right)$ were estimated from the experimental data. They were calculated using modified Arrhenius type equation related to surface coverage $(\Theta)$ as follows ${ }^{11}$ :

$$
\begin{array}{ll}
\theta=\left[1-\frac{C_{e}}{C_{i}}\right] & \text { or } \frac{C_{e}}{C_{i}}=1-\theta \\
S^{*}=(1-\theta) e^{\frac{-E a}{R T}} & \\
\ln S^{*}=\ln (1-\theta)-\frac{E_{a}}{R T} & \\
\ln (1-\theta)=\ln S^{*}+\frac{E_{a}}{R T} &
\end{array}
$$

The sticking probability $S^{*}$, is a function of the adsorbate / adsorbent system under investigation, its value lies in the range $0<S^{*}<1$ for preferable process and is dependent on the temperature of the system ${ }^{11}$. The ' $\theta$ ' is the surface coverage, which can be calculated from equation 4. The values of Ea and $S^{*}$ can be calculated from slope and intercept of the plot of $\ln (1-\theta)$ versus $1 /$ T respectively (Figure $2 \&$ Table 2). The values of Ea were found to be $2.438,4.034,8.399$ and $8.119 \mathrm{~kJ} \mathrm{~mol}^{-1}$ for the adsorption of $\mathrm{Cr}(\mathrm{VI})$ onto MPGP. The positive values of Ea indicate the endothermic nature of the adsorption process which are in agreement with the positive values of $\Delta \mathrm{H}^{\circ}$ and lie in the range of physisorption. The sticking probability values were less than 1 (Table 2), which indicates that the probability of the $\mathrm{Cr}(\mathrm{VI})$ ions to stick on surface of MPGP is very high as $\mathrm{S}^{*}<<1$, these values confirm that, the sorption process is physisorption.

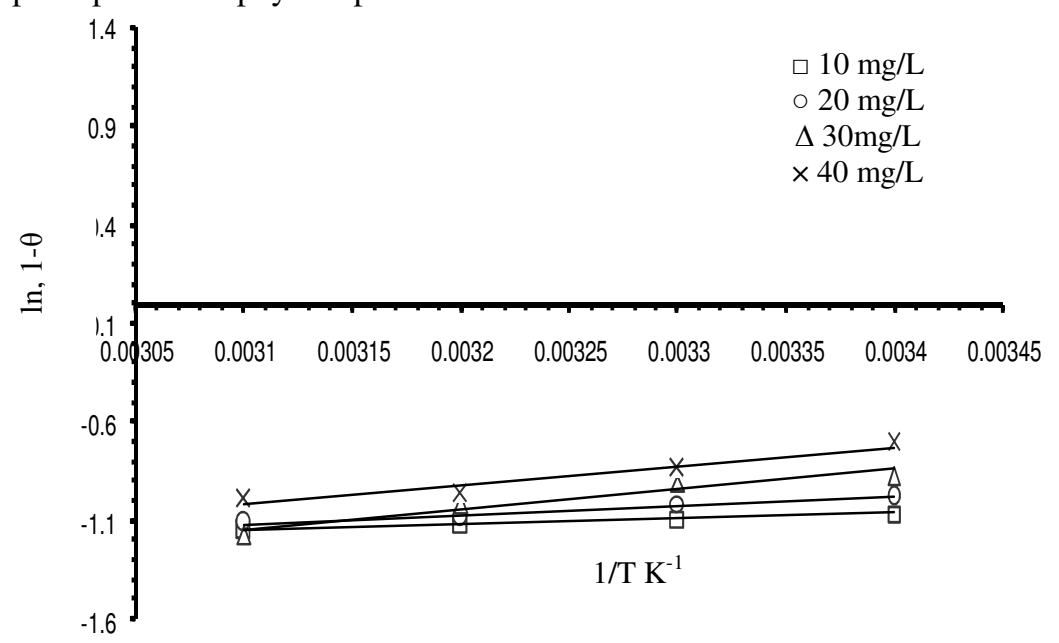

Figure 2. Plot of $\ln (1-\theta)$ vs. reciprocal temperature for the adsorption of $\mathrm{Cr}(\mathrm{VI})$ onto MPGP. 
Table 2. Sticking probability and activation energy for the adsorption of $\mathrm{Cr}(\mathrm{VI})$ onto MPGP.

\begin{tabular}{cccc}
\hline Cr(VI) conc. mg/L & $\mathrm{Ea} \mathrm{kJ} \mathrm{mol}^{-1}$ & $\mathrm{~S}^{*}$ & $\mathrm{R}^{2}$ \\
\hline 10 & 2.438 & 0.1279 & 0.9980 \\
20 & 4.034 & 0.0727 & 0.9736 \\
30 & 8.399 & 0.0139 & 0.9330 \\
40 & 8.119 & 0.0175 & 0.9384 \\
\hline
\end{tabular}

\section{Effect of temperature on the adsorption of Cr(VI) onto FMPGP}

The thermodynamic parameter $\Delta \mathrm{H}^{\circ}$ and $\Delta \mathrm{S}^{\circ}$ were determined from applying of Van't Hoff equation (equation 3). The plot of $\log \mathrm{K}_{\mathrm{o}}$ versus $1 / \mathrm{T}$ (Figure 3 ) can be used to estimate $\Delta \mathrm{S}^{\circ}$ and $\Delta \mathrm{H}^{\circ}$ where, the intercept is equal to $\Delta \mathrm{S} / 2.303 \mathrm{R}$ and the slope is equal to $-\Delta \mathrm{H} / 2.303 \mathrm{R}$. The Gibbs free energy $\Delta \mathrm{G}^{\circ}$ were determined from equation 2 . The values of these parameters are tabulated in Table 3. The positive values of $\Delta \mathrm{H}^{\circ}$ show the endothermic nature of the adsorption process. The values of $\Delta \mathrm{H}^{\circ}$ are within the range of 1 to $93 \mathrm{~kJ} \mathrm{~mol}^{-1}$ indicates the physisorption ${ }^{7}$. The values of $\Delta S^{\circ}$ (Table 3) are positive and higher than that in the case of $\mathrm{Cr}(\mathrm{VI})$ adsorption on MPGP, which indicate an increase in disorder and randomness at the solid-solution interface during the adsorption of $\mathrm{Cr}(\mathrm{VI})$, this behavior can be attributed to the decreases of water molecule around the solute or surface during the adsorption process which lead to increase in degree of freedom of water molecule ${ }^{8,12}$. The negative values of $\Delta \mathrm{G}^{\circ}$ (Table 3) show the adsorption is highly favorable and spontaneous. The same behavior was also observed, that the negative values of $\Delta \mathrm{G}^{\circ}$ increases with increase in temperature.

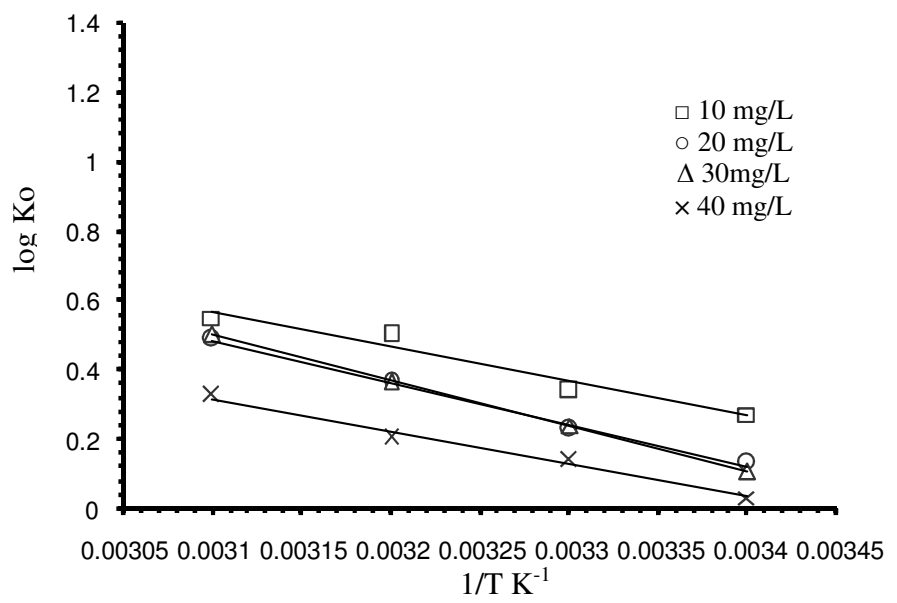

]Figure 3. Plot of Van't Hoff equation for the adsorption of $\mathrm{Cr}(\mathrm{VI})$ onto FMPGP.

Table 3. Thermodynamic parameters for the adsorption of $\mathrm{Cr}(\mathrm{VI})$ onto FMPGP.

\begin{tabular}{cccccccc}
\hline $\mathrm{Cr}(\mathrm{VI})$ Con. & $\Delta \mathrm{H}^{\circ}$ & $\Delta \mathrm{S}^{\circ}$ & \multicolumn{5}{c}{$\Delta \mathrm{G}^{0}, \mathrm{~kJ} \mathrm{~mol}^{-1}$} \\
\cline { 4 - 8 } $\mathrm{mg} / \mathrm{L}$ & $\mathrm{kJ} \mathrm{mol}^{-1}$ & $\mathrm{~J} \mathrm{~mol}^{-1}$ & $20{ }^{0} \mathrm{C}$ & $30{ }^{0} \mathrm{C}$ & $40{ }^{0} \mathrm{C}$ & $50{ }^{0} \mathrm{C}$ & $\mathrm{R}^{2}$ \\
\hline 10 & 19.19 & 70.32 & -1.525 & -1.960 & -3.013 & -3.405 & 0.9541 \\
20 & 23.10 & 80.83 & -0.731 & -1.320 & -2.173 & -3.010 & 0.9961 \\
30 & 25.03 & 87.14 & -0.599 & -1.388 & -2.202 & -3.088 & 0.9999 \\
40 & 18.06 & 62.03 & -0.178 & -0.809 & -1.213 & -2.009 & 0.9874 \\
\hline
\end{tabular}


The activation energy (Ea) and sticking probability $\left(\mathrm{S}^{*}\right)$ were calculated from equation 7. From the plot $\ln (1-\theta)$ versus $1 / \mathrm{T}$ (Figure 4 ) Ea and $\mathrm{S}^{*}$ value can be calculated. The positive values of Ea indicate the endothermic nature of the adsorption, which are in agreement with positive values of $\Delta \mathrm{H}^{\circ}$ (Table 4$)$. the sticking probability values were less than 1 and even less than values of $\mathrm{Cr}(\mathrm{VI})$ adsorption on MPGP, which indicate that the probability of $\mathrm{Cr}(\mathrm{VI})$ ions to stick on surface of FMPGP is very high as long $\mathrm{S}^{*}<<1$ (Table 4). These values confirm that the sorption is physisorption.

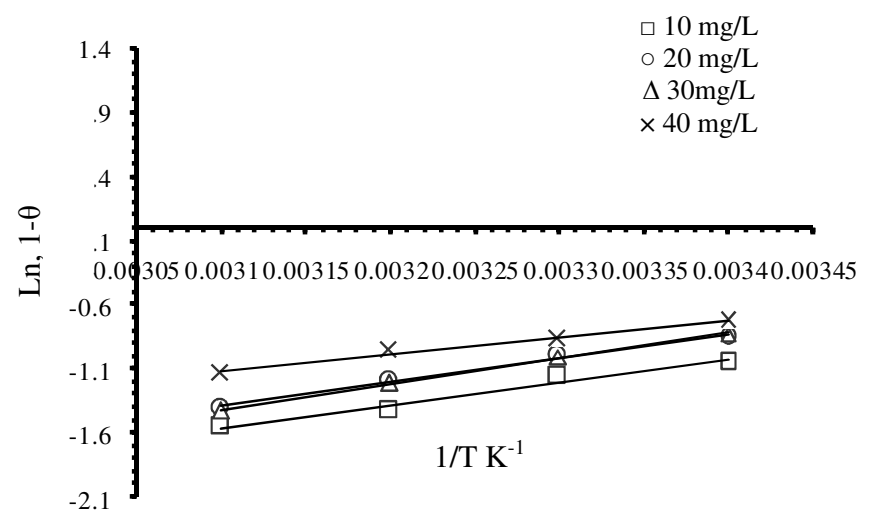

Figure 4. Plot of $\ln (1-\theta)$ vs. reciprocal temperature for the adsorption of $\mathrm{Cr}(\mathrm{VI})$ onto FMPGP.

Table 4. Sticking probability and activation energy for the adsorption of $\mathrm{Cr}(\mathrm{VI})$ onto FMPGP.

\begin{tabular}{cccc}
\hline $\mathrm{Cr}(\mathrm{VI})$ Conc., $\mathrm{mg} / \mathrm{L}$ & $\mathrm{Ea}, \mathrm{kJ} \mathrm{mol}^{-1}$ & $\mathrm{~S}^{*}$ & $\mathrm{R}^{2}$ \\
\hline 10 & 13.81 & 0.0013 & 0.9539 \\
20 & 15.32 & 0.0008 & 0.9904 \\
40 & 16.72 & 0.0005 & 0.9979 \\
60 & 10.85 & 0.0057 & 0.9825 \\
\hline
\end{tabular}

\section{References}

1 Karthikeyan T, Rajgopal S and Miranda L R, J Hazard Mater., 2005, 124(1-3), 192-199.

2 Torresdey J L C, Tiemann K J and Armendariz V, J Hazard Mater., 2000, 80(1-3), 175-188.

3 Gao H, Liu Y, Zeng G, Xu W, Li T and Xia W, J Hazard Mater., 2007, 150 (2), 446-452.

4 Verma A, Chakraborty S and Basu J K, Separ Purif Tech., 2006, 50(3), 336-341.

5 Li Q, Zhai J, Zhang W, Wang M and Zhou J, J Hazard Mater., 2007, 144(1), 163-167.

6 Saiful A A, Ghaniey Liew A, Suhardy D, Farizul H K, Irfan M D, Am J Appl Sci., 2005, 2(11), 1499-1503.

7 Arivoli S, Hema M, Karuppaiah M, and Saravanan S, E Journal of Chemistry, 2008, 5(4), 820-831.

8 Arivoli S and Thenkuzhali M, E Journal of Chemistry, 2008, 5(2), 187-200; Arivoli S and Hema M, Int J Phys Sci., 2007, 2, 10-17.

10 Arivoli S Kalpana K, Sudha R and Rajachandrasekar T, E Journal of Chemistry, 2007, 4, 238-254.

11 Nevine K A, J Hazardous Materials, 2009, 165(1-3), 52-62.

12 Sujatha M, Greetha A, Sivakumar P and Palanisamy P N, E Journal of Chemistry, 2008, 5(4), 742-753. 


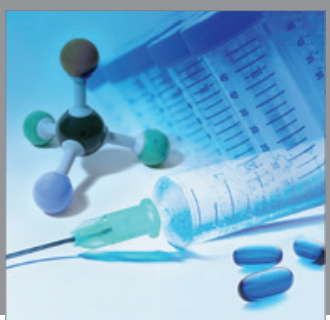

International Journal of

Medicinal Chemistry

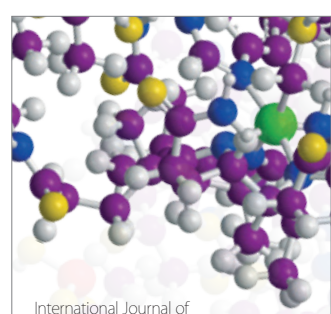

Carbohydrate Chemistry

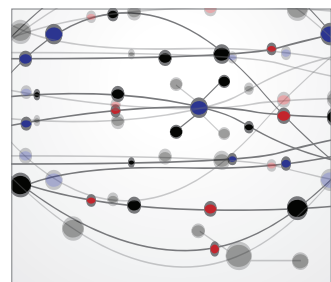

The Scientific World Journal
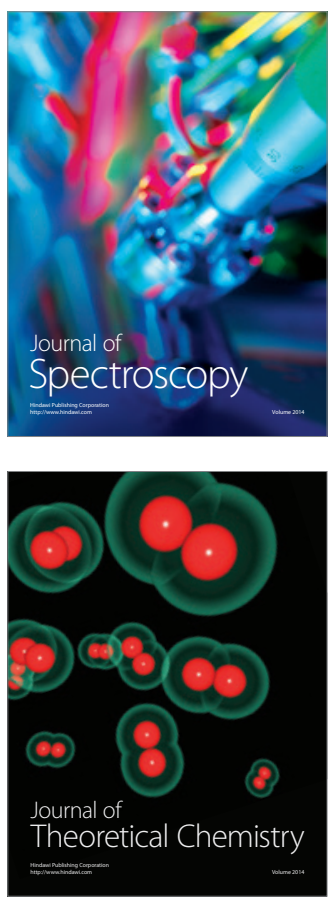
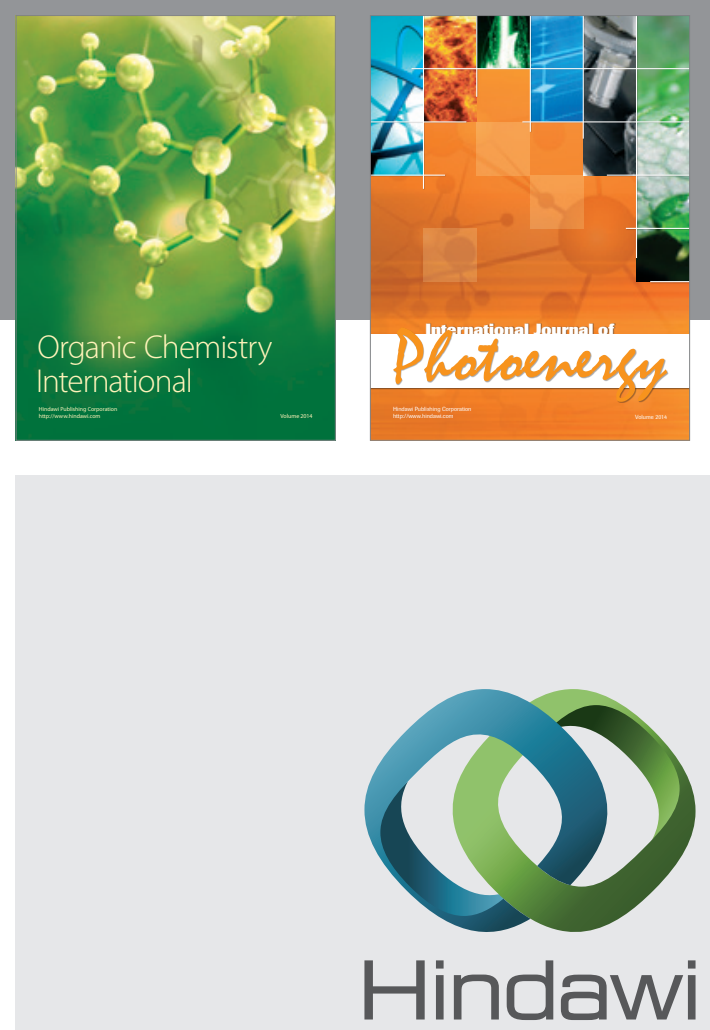

Submit your manuscripts at

http://www.hindawi.com
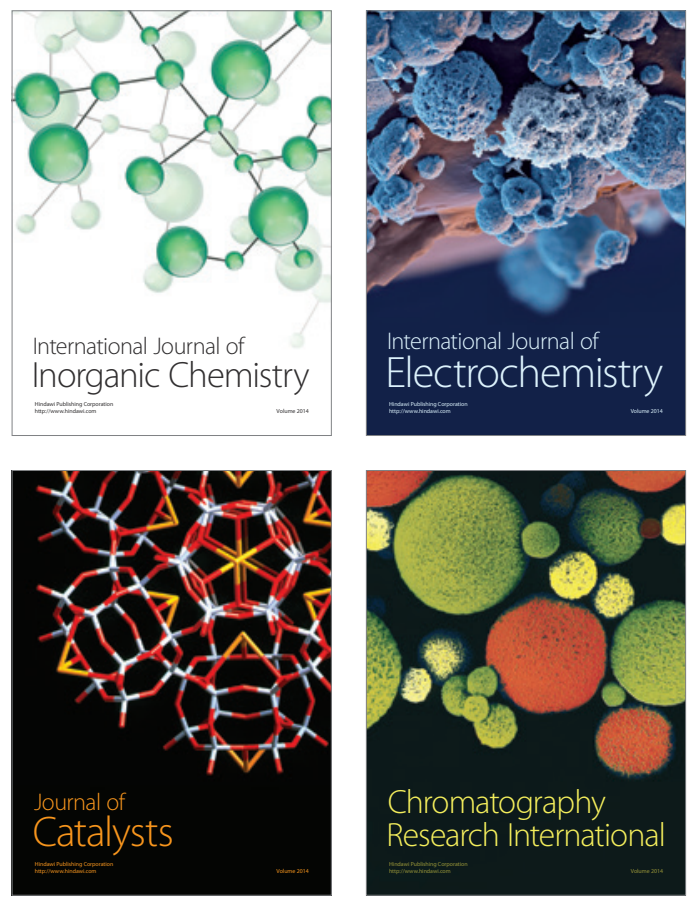
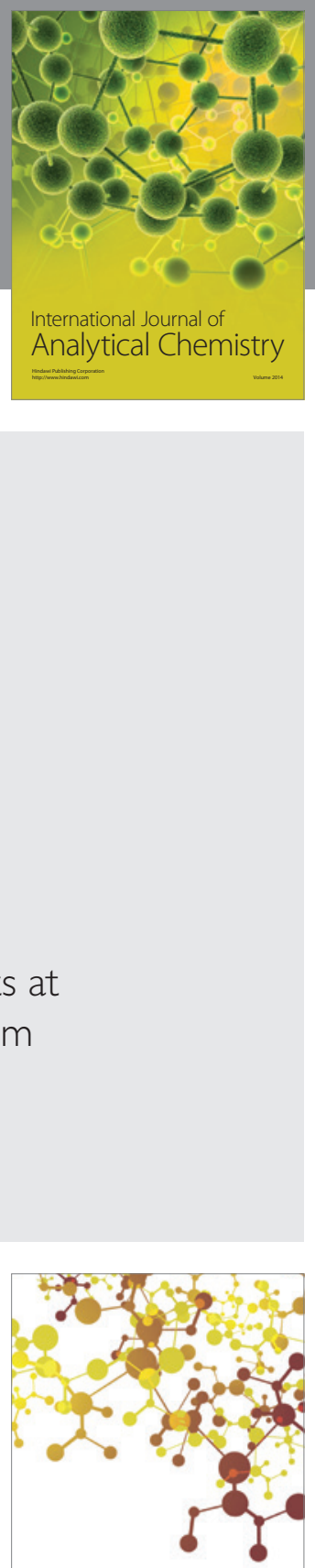

Journal of

Applied Chemistry
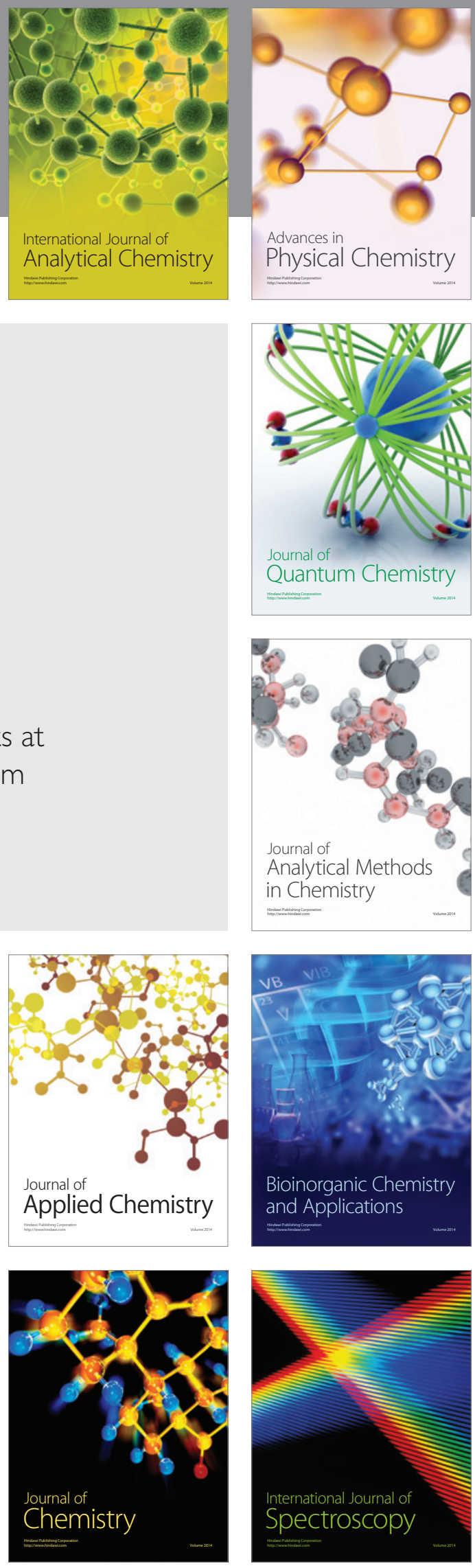